\title{
A study of the correlation between mean platelet volume and diabetic retinopathy in patients with type 2 diabetes mellitus
}

\author{
Yeruva Poulina Deepthi Reddy ${ }^{1}$, S. Vithiavathi ${ }^{2 *}$, G. Kalaiselvi ${ }^{3}$ \\ ${ }^{1}$ Post Graduate, ${ }^{2}$ Professor and HOD,${ }^{3}$ Associate Professor, ${ }^{1,2}$ Dept. of General Medicine, ${ }^{3}$ Dept. of Ophthamology, Aarupadai Veedu \\ Medical College and Hospital, Pondicherry, India
}

*Corresponding Author: S. Vithiavathi

Email: drsvv99@gmail.com

\begin{abstract}
Diabetic retinopathy (DR), a kind of micro vascular lesion that is detected on fundus examination, accounts for 40 percent of diabetics over 40 years of age. To determine the correlation of mean platelet volume with diabetic retinopathy.

Methodology: Hospital based Case- Control study. 50 patients diagnosed as Type-2 diabetes mellitus with defined diabetic retinopathy and 50 patients with age and sex matched without the case disease. To all the patients mean platelet volume was done and comparing the significant difference of mean platelet volume between diabetics with retinopathy (cases) and control groups.

Results: The mean platelet volume of the diabetic retinopathy and controls were $11.77+1.40$ and $7.55 \pm 0.35$. Regarding fasting glucose level for diabetic retinopathy and controls were $196.04+13.2$ and $103.57 \pm 12.16$ which is significantly higher than the controls $(\mathrm{p}$ value $<0.005)$. Likewise the post prandial values for diabetic retinopathy $329.64+47.65$, which is significantly higher than the control 160.9 +14.99 . ( $\mathrm{p}$ value $<0.005$ ). The HbA1c values for the diabetic retinopathy seems to be $9.78 \pm 1.01$ which is significantly higher than the control groups 5.48+0.94. (p value $<0.005)$.
\end{abstract}

Conclusion: Mean platelet volume was reported to be raised in diabetic retinopathy patients compared to the healthy population.

Keywords: Diabetic Retinopathy, Mean Platelet Volume, HbA1c, Diabetes Mellitus.

\section{Introduction}

Diabetes mellitus (DM) is a major global health problem. According to estimates of the World Health Organization, the number of people with DM has risen from 108 million in 1980 to 422 million in 2018 there. Diabetic patients have an increased risk of developing micro and macro vascular disease, and platelets may be involved as a causative factor with respect to altered platelet morphology and function. ${ }^{1,2}$

Diabetic retinopathy (DR), a kind of micro vascular lesion that is detected on fundus examination, accounts for 40 percent of diabetics over 40 years of age. It is the main cause of impaired vision and even blindness in diabetics. Platelet volume, a marker of the platelet function and activation, is measured as mean platelet volume (MPV).

Normal mean platelet volume in healthy subjects ranges between 7.2 and $11.7 \mathrm{fL}$. Larger platelets are younger and exhibits more activity. Altered platelet morphology and function has been observed in diabetes in the form of enhanced platelet activity which may contribute to this "prothrombotic state". 3

The glycated hemoglobin $\mathrm{A}(\mathrm{HbA} 1 \mathrm{c})$ is a validated and a reliable indicator of blood glucose control in DM subjects and has been studied in relation to MPV. ${ }^{4}$ The aim and objectives of this present study is to determine the correlation of mean platelet volume with diabetic retinopathy.

\section{Materials and Methods}

\section{Study Design \& Study setting}

This is a Hospital based Case- Control study. This study was carried out in Department of General Medicine, Aarupadai Veedu Medical College \& Hospital, and Pondicherry in 2019.

\section{Study participants and Sampling technique}

50 patients diagnosed as Type- 2 diabetes mellitus with defined diabetic retinopathy and 50 patients with age and sex matched without the case disease. The cases and controls were selected through Non-Probability purposive sampling according to the inclusion and exclusion criteria. We included the patients age group $>18$ yrs Males and Females both IN and OUT patients department. Patients who are diagnosed as diabetic and with defined diabetic retinopathy are taken as cases. Diabetes is diagnosed based on ADA (American diabetes association) Criteria. In control group age and sex matched healthy population.

The patients with Abnormal platelet count $(<1$ and $>4$ lakhs/cumm). Patients taking drugs that affect platelet function (aspirin, warfarin, Ticlopidine or heparin) and on statin therapy. Male patients with $\mathrm{Hb}<12 \mathrm{mg} / \mathrm{dl}$ and females with $\mathrm{Hb}<10 \mathrm{mg} / \mathrm{dl}$ and patients with pregnancy and malignancy were excluded from the study.

\section{Study procedure}

To all the patients mean platelet volume was measured and comparing the significant difference of mean platelet volume between diabetics with retinopathy (cases) and age and sex matched healthy population (controls) and the Fasting blood glucose - measured by glucose oxidase method in the auto analyser, Post prandial blood glucose - measured by glucose oxidase method in the auto analyser, Glycolated hemoglobin (HbA1c) - measured by high-performance liquid chromatography method. Complete blood picture - measured by automatic blood counter, Mean platelet volume measured by automatic blood counter, Renal function testsurea, Creatinine and Urine routine were done. 


\section{Statistical analysis}

The data was analysed using SPSS version 20. The quantitative variables were presented as mean $\pm \mathrm{SD}$ and in Percentages using chi-square test as test of significance.

\section{Ethical issues}

This study was approved by Institutional Ethics Committee. After taking informed consent in Tamil and English the participants were included in the study.

\section{Results}

Table 1: Demographic details of the study participants in cases and control groups

\begin{tabular}{|l|c|c|}
\hline & Diabetic Retinopathy & Controls \\
\hline Age in mean years & $56.9 \pm 12.5$ & $58.5 \pm 12.4$ \\
\hline Sex Distribution & Male -29 & Male -20 \\
& Female -21 & Female - 30 \\
\hline
\end{tabular}

Table 1, Describes the Demographic details of the study participants in cases and control groups. In this study in Diabetic Retinopathy group is the mean years of age is $56.9 \pm 12.5$ and in the control group is $58.5 \pm 12.4$. Regarding sex distribution in Diabetic retinopathy 29 were male and 21 were female. In control groups males were 20 and females were 30 .

Table 2: Comparison of mean platelet volume and blood glucose values in diabetic retinopathy cases and controls

\begin{tabular}{|l|c|c|}
\hline & Diabetic Retinopathy & Controls \\
\hline Mean Platelet Volume & $11.77 \pm 1.40$ & $7.55 \pm 0.35$ \\
\hline Fasting glucose & $196.04 \pm 13.2^{*}$ & $103.57 \pm 12.16$ \\
\hline Post Prandial & $329.64 \pm 47.65^{*}$ & $160.9 \pm 14.99$ \\
\hline HbA1c & $9.78 \pm 1.01^{*}$ & $5.48 \pm 0.94$ \\
\hline
\end{tabular}

$* \mathrm{P}$ value $<0.005$

As seen in the above table, the mean platelet volume of the diabetic retinopathy and controls were $11.77+1.40$ and $7.55+$ 0.35. Regarding fasting glucose level for diabetic retinopathy and controls were $196.04+13.2$ and $103.57 \pm 12.16$ which is significantly higher than the controls ( $\mathrm{p}$ value $<0.005$ ). Likewise the post prandial values for diabetic retinopathy $329.64+$ 47.65 , which is significantly higher than the control $160.9+14.99$. ( $\mathrm{p}$ value $<0.005$ ). The HbAlc values for the diabetic retinopathy seems to be $9.78 \pm 1.01$ which is significantly higher than the control groups $5.48 \pm 0.94$. (p value $<0.005$ ).

Table 3: Percentages of cases in grades of diabetic retinopathy

\begin{tabular}{|l|c|}
\hline Mild NPDR & $28(56 \%)$ \\
\hline Moderate NPDR & $14(28 \%)$ \\
\hline Severe NPDR & $6(12 \%)$ \\
\hline Very Sever NPDR & $2(4 \%)$ \\
\hline
\end{tabular}

The above table shows the frequency percentages of the cases in grades of diabetic retinopathy. The Mild NPDR was 28 (56\%), Moderate NPDR was 14 (28\%), Severe NPDR was 6 (12\%) and very severe NPDR was $2(4 \%)$.

Table 4: Correlation of grades of diabetic retinopathy with mean platelet volume

\begin{tabular}{|l|c|c|c|c|}
\hline & $\begin{array}{c}\text { Mild } \\
\text { NPDR }\end{array}$ & $\begin{array}{c}\text { Moderate } \\
\text { NPDR }\end{array}$ & $\begin{array}{c}\text { Severe } \\
\text { NPDR }\end{array}$ & $\begin{array}{c}\text { Very Severe } \\
\text { NPDR }\end{array}$ \\
\hline Mean Platelet Volume & $9.77 \pm 0.43$ & $10.53 \pm 0.57$ & $12.89 \pm 0.32$ & $13.72 \pm 0.69$ \\
\hline $\begin{array}{l}\text { Fasting blood } \\
\text { Glucose }\end{array}$ & $122.13 \pm 15.63$ & $153.03 \pm 20.78$ & $196.04 \pm 13.22$ & $210.92+30.57$ \\
\hline $\begin{array}{l}\text { Post Prandial } \\
\text { Glucose }\end{array}$ & $232.16 \pm 26.49$ & $289.34 \pm 32.81$ & $329.64 \pm 47.65$ & $356.42 \pm 40.43$ \\
\hline HbA1c & $6.89 \pm 0.78$ & $8.23 \pm 2.51$ & $9.78 \pm 1.01$ & $11.63 \pm 2.03$ \\
\hline
\end{tabular}

In the above table, the correlation of grades of diabetic retinopathy with mean platelet volume was explained. The Mean Platelet Volume, Fasting blood glucose, Post prandial and HbA1c for the mild NPDR were 9.77 $\pm 0.43,122.13 \pm 15.63,122.13+15.63$ and 6.89+0.78. In Moderate NPDR the above mentioned values were 10.53+0.57, 153.03+20.78, 289.34+32.81 and 8.23+2.51. For Severe NPDR it is as $12.89 \pm 0.32,196.04+13.22,329.64 \pm 47.65$ and $9.78+1.01$. And for the Very Severe NPDR the Mean Platelet Volume was 13.72 \pm 0.69 and FBS, PPBS, HbA1c were 210.92+30.57, 356.42 \pm 40.43 and 11.63 \pm 2.03 . 


\section{Discussion}

The mean platelet volume is a recently emerging risk factor for atherothrombosis in Diabetes Mellitus. Many studies have shown that increased MPV is a risk factor for myocardial infarction, cerebral ischemia, TIA and diabetic microvascular complications like albuminuria. ${ }^{5,6} \mathrm{We}$ found significant differences in Mean platelet volume, Fasting blood glucose, Post prandial glucose and HbA1c values in diabetic group when compared with normal healthy controls.

In our study the mean platelet volume was found to be $11.77 \pm 1.40$ in Diabetic retinopathy group and in $7.55+0.35$ control group. Which is similar to the study conducted by Dolasik et al. ${ }^{7}$ on 60 newly diagnosed diabetic subjects and found a higher MPV values compared with normal controls and MPV values were improved within six months of metformin therapy. These findings are in consistent with the present study. Our study revealed a positive correlation between MPV and $\mathrm{HbA} 1 \mathrm{c}$ which is consistent with the results of Dalamaga et al. ${ }^{8}$ that conducted a prospective study on diabetics, diabetic-myelodysplastic and normal healthy controls and found elevated MPV.

The MPV was found to be positively correlated with the HbA1c, that is highly consistent with the present work. The Demirtunc et al..$^{9}$ conducted a study on diabetics and controls and found close relationship between platelet hyperactivity as measured by MPV and poor glycemic control. In his study, the improvement in glycemic control, normalized the MPV values and hence reported that platelet hyperactivity may be a risk factor for vascular complications in diabetics. These findings support our present study as diabetic patients with higher $\mathrm{HbAlc} \%$ were having higher MPV values, rising parallel with each other. MPV was strongly associated with complications like Retinopathy which was similar to studies done by Ates et al. ${ }^{12}$ Similarly in our study the mean platelet volume was increasing with the grades of Diabetic retinopathy along with the FBS.PPBS and $\mathrm{HbA1c}$.

MPV is positively correlated with platelet adhesion and aggregation, the higher the MPV values, the higher the rate and function of platelets. Recent research found that MPV was strongly and independently associated with the presence and severity of diabetes and there were great significance of cardio-vascular complications in diabetes mellitus. ${ }^{10}$ The larger the MPV, the more likely formation of thrombosis, and in other hand, vascular endothelial injury triggers platelet adhesion and aggregation to accelerate thrombosis. Subgroup analysis exhibited that there was a significant difference in MPV values between NPDR and PDR.As the grade of diabetic retinopathy increased there is significant increase in MPV. We reached conclusions that DR grade resulted in the heterogeneity and the MPV level was also upregulated in higher DR grades as in study conducted by Papanas et al. ${ }^{11}$

As the $\mathrm{HbA} 1 \mathrm{c}$ is a validated indicator of glycaemic control and has linear relationship with diabetic vascular complications, hence it is concluded that MPV may also be taken as an indicator of glycaemic status and diabetic vascular complications beside $\mathrm{HbA} 1 \mathrm{c}$ but this needs further large scale, prospective studies to be conducted.

\section{Conclusion}

Mean platelet volume was reported to be raised in diabetic retinopathy patients particularly in those having uncontrolled blood sugars. The MPV was positively correlated with $\mathrm{HbA1c}$ and blood glucose values. We recommend that MPV can be used as a simple and cost- effective tool to monitor the progression of the diabetic retinopathy.

\section{Source of Funding}

None.

\section{Conflict of Interest}

None.

\section{References}

1. Ji S, Zhang J, Fan X. The relationship between mean platelet volume and diabetic retinopathy. Diabetol Metab Syndr. 2019;11:25.

2. Sertbas Y, Sertbas M, Okuroglu N, Ozturk MA, Abacar KY, Ozdemir A. Mean platelet volume changes before and after glycated hemoglobin $\left(\mathrm{HbA}_{1 \mathrm{c}}\right)$ improvement in a large study population. Arch Med Sci. 2017;13(4):711-5.

3. Turgutalp K, Ozhan O, Akbay E, Tombak A, Tiftik N, Ozcan T, et al. Mean platelet volume and related factors in patients at different stages of diabetic nephropathy: a preliminary study. Appl Thromb Hemost. 2014;20:190-5.

4. American Diabetes Association. Standards of medical care in diabetes. Diabet Care. 2012;35(Suppl 1):S11-S63.

5. Cheng H, Huang HS, Park HK, Chun MY and Sung JY. The role of mean platelet volume as a predicting factor of asymptomatic coronary artery disease. Korean J Fam Med. 2010;8:600-6.

6. Targutalp K, Ozhan O, Akbay E, Tiftik N Yilmaz S, Kiykim A. Mean platelet volume and related factors in patients at different stages of diabetic nephropathy. Nephro Dial Transplant. 2012;27(2):167-77.

7. Dolasik I, Sener SY, Celebi K, Aydin ZM, Korkmaz U, Canturk $Z$. The effect of metformin on mean platelet volume in diabetic patients. Platelets. 2012;4.

8. Dalamaga M, Karmaniols K, Lekka A, Antonakos G, Thrasyvoulides A, Papadavid E, et al. Platelet markers correlate with glycemic indices in diabetic, but not diabeticmyelodysplastic patients with normal platelet count. Dis Marker. 2010;29:55-61.

9. Demirtunc R, Duman D, Basar M, Bilgim M, Teomete M, Garip $\mathrm{T}$. The relationship between glycemic control and platelet activity in type 2 diabetes mellitus. J Diabet Complic. 2009;23:89-94.

10. Shah B, Sha D, Xie D, Mohler ER, Berger JS. The relationship between diabetes, metabolic syndrome, and platelet activity as measured by mean platelet volume: the national health and nutrition examination survey, 1999-2004. Diabetes Care. 2012;35:1074-8.

11. Papanas N, Symeonidis G, Maltezos E, Mavridis G, Karavageli E, Vosnakidis T, et al. Mean platelet volume in patients with type 2 diabetes mellitus. Platelets. 2009;15:475-8.

12. Ateş O, Kiki I, Bilen H, Keleş M, Koçer I, Kulaçoğlu DN, et al. Association of mean platelet volume with the degree of retinopathy in patients with diabetes mellitus. Eur J Gen Med. 2009;6:99-102.

How to cite: Reddy YPD, Vithiavathi S, Kalaiselvi G. A study of the correlation between mean platelet volume and diabetic retinopathy in patients with type 2 diabetes mellitus. Panacea J Med Sci. 2020;10(1):10-2. 